\title{
ABSTRACTS OF POSTERS
}

\section{Waterlogging effects on Salix viminalis}

\author{
Paul A. Attwood1,2, Edward I. Newman' and Michael B. Jackson ${ }^{2}$ \\ Department of Botany ${ }^{1}$ and Agricultural Science ${ }^{2}$, University of Bristol, U.K.
}

Willow is common in riparian zones that are frequently waterlogged. There is interest in fast-growing willow for biomass, and land that is subject to flooding may be suitable for this purpose. Accordingly, we have studied the ability of willow to withstand poorly aerated root environments under controlled conditions.

Rooted cuttings of Salix viminalis L. cv. Bowles Hybrid were grown in aerated or deoxygenated nutrient solution. They showed considerably reduced root growth when dissolved oxygen partial pressures were reduced from $21 \mathrm{kPa}$ to $0-2 \mathrm{kPa}$. At below $1 \mathrm{kPa}$, adventitious roots extended at about one third the rate of aerated roots. Growth in dry mass was also curtailed. Root growth under these conditions could have been sustained either by oxygen transported to the roots internally from the shoot or by the root's ability to respire and grow without oxygen. These possibilities are being examined further.

Aerenchyma (internally interconnected gas-filled space) is the most likely pathway for oxygen transport to the roots, from aerial parts. Therefore roots were investigated for the presence or absence of aerenchyma. Roots of all treatments had similar amounts of aerenchyma (20-30\% of the cortex). Aerenchyma formation in Salix viminalis therefore appears to be constitutive and is not induced by poorly aerated conditions, as happens in cereal roots such as wheat and maize. In the latter species, ethylene (ethene) is thought to be responsible for inducing aerenchyma by promoting lytic breakdown of cortical cells. To test whether ethylene is active in willow, silver nitrate, a well-known inhibitor of ethylene action was applied. Silver nitrate was toxic at concentrations of $0.05 \mathrm{mg} \mathrm{l}^{-1}$ and above but did not inhibit aerenchyma formation at lower non-toxic concentrations. Ethylene therefore is unlikely to be involved in aerenchyma development.

\section{A preliminary account of chromosome numbers in the Salix - section Retusae}

\section{W. Büchler}

Flurystrasse $12, \mathrm{CH}-8620$ Wetzikon, Switzerland

Salix serpyllifolia Scop., S. retusa L. and $S$. kitaibeliana Willd. differ almost only by quantitative features. The dwarf of the three, $S$. serpyllifolia has long been regarded 
as a subspecies or variety of $S$. retusa, which arose under the hard climatic conditions of the high mountains. Rechinger (1938) first proposed that $S$. retusa and $S$. kitaibeliana could be polyploid descendants of $S$. serpyllifolia. Recent chromosome counts made by several authors seem to confirm this but suggest that the situation might even be more complex (Table 1).

At first sight, there doesn't seem to be a simple coherence between species and polyploidy level. In each taxon we find two or even three different chromosome numbers. This might be because the species are primarily defined by their morphological (in this case quantitative) characters and not necessarily according to their sterility barriers (e.g. different polyploidy levels) to other species. Quantitative features may overlap between neighbouring polyploidy levels from genetic variability and response to environmental influences. It is concluded that both $S$. retusa and $S$. kitaibeliana do not contain the diploid level.

The situation becomes somewhat clearer when considering the geographical distribution of the polyploidy levels. The diploid $S$. serpyllifolia appears to be restricted to the central part of the Alps. Tetraploid plants of all three species are reported either from the Tatra mountains (Poland and C.S.F.R.) or at least from authors of these countries. Plants of the highest polyploidy levels $(2 n=114 \ldots 152)$ were found in the Alps, the Tatra- and the Pirin-mountains (Bulgaria). They often show more or less serious irregularities with losses of chromosomes during meiosis (Büchler 1986). Some of them were found to be aneuploid, with an outset point at $2 n=152$. Others, like the hybrids of $S$. retusa with $S$. nigricans Sm. and $S$. bicolor Ehrh. started at $2 n=7 \times 133$ (resulting from a combination of hexaploid and octoploid parents). Descendants of these plants may have chromosome numbers floating between $2 n=114 \ldots 152$, in the long-term probably with a downward trend.

\section{References}

Büchler, W. 1985. Neue Chromosomenzählungen in der Gattung Salix. Botanica Helvetica 95, 165-75. Büchler, W. 1986. Neue Chromosomenzählungen in der Gattung Salix. 2. Teil. Botanica Helvetica 96/2, $135-43$.

Chmelař, J. 1979. The Taxonomic Importance of Chromosome Numbers in the Genus Salix L. Lesnictvi 25, 411-15.

Izmaiłow, R. 1980. Cytological studies in Salix L. I. Acta Biol. Cracov 22, 101-11.

Rechinger, fil. K.H. 1938. Salicologische Fragmente 1-4. Feddes Repertonium, 45, 87-94.

Löve, A. \& Love, D. 1961. Chromosome numbers of central and northwest European plant species. Opera Botanica 5, 118-21.

\section{Salix acmophylla Boiss. - another Salix species with two loose bud scales?}

\section{W. Büchler}

Flurystrasse 12 , Ch-8620, Wetzikon, Switzerland

In most willow species axillary buds have a single bud scale formed by the fusion of two prophylls on both abaxial and adaxial side (see Figs 1 and 2). The first two cataphylls appear usually in the transversal plain while the following pass over in the spiral fashion of about 2/5 divergence (Kimura \& Sugaya 1965). 